\title{
An ethical audit of the SEND CoP 2015: professional partnership working and the division
}

of ethical labour

\section{Introduction}

Contemporary special educational needs and disability (SEND) policy reform in England can only be understood in the wider context of educational and social policy reform (Norwich, 2014). This wider policy reform frame is characterised by a shift from education seen as a social good to that of an economic good, where the virtues of competition, privatisation and individual liberty of the free market economy are promoted as the most effective mechanism for the distribution of social resources (Garratt \& Forrester, 2012). SEND policy is particularly contested as it brings into relief the contradictions between key social values, including those of justice and fair opportunity versus choice and preference; and high academic standards versus social inclusion (Gewirtz \& Cribb, 2009). The SEND Code of Practice (CoP) 2015 (DfE and DoH, 2015) is an exemplar of these competing values, with its stated intention of ensuring coherent, transparent and uniform provision for some of the most vulnerable in society (p.17), whilst at the same time promising more choice and personalised services based on preference (p.19).

The 2015 Code can therefore never merely be understood as a manual that directs professional practice in delivering better services and more effective partnership working between agencies and with parents, but must also be seen as a "discursive regime" that "comes with ethical baggage of its own" (Cribb \& Ball, 2005, p.126). Whilst the Code may be necessary for directing consistent professional action, it may not be sufficient for ensuring ethical professional conduct. In this article I identify two specific problems associated with the 2015 Code. One is a pre-occupation with implementation demands which obscures deeper unease and leaves moral doubt habitually unexplored. The second is the construction of the 'good' SEND professional as someone who conceals complexity, trades in professional certainties and can offer 'straightforward' advice in response to customer demand.

Whilst the 2015 SEND Code was promoted as a radical departure from previous policy, for many front-line professionals there are strong continuities in their professional practises. 
Nevertheless, the introduction of a new, and newly statutory, Code merits a consideration of this 'ethical baggage', which is currently insufficiently examined and which I seek to redress with the exploratory study this article reports on. I will explain and address particular aspects of the 2015 Code further in my data analysis and discussion sections.

The study assumes a professionalism that insists on values and ethics and that rejects a partnership concept devoid of personhood and argues for the cultivation of a professional identity which includes a strong moral core. By means of an ethical audit I explore the policy ethics and ethical effects (Cribb \& Ball, 2005) for partnership working (both positive and detrimental) that arise from the introduction of the SEND CoP 2015. The study asks what kinds of ethical choices and dilemmas the intensified discourse of partnership working in the context of neoliberal policy reform generates in SEND professionals; and what new dispositions and moral identities the heightened emphasis on partnership working creates. I also consider the division of ethical labour (Cribb, 2009) and its implications for partnership working and the design of particular roles. Before describing my study, participants and approaches to data analysis, I first set the context by discussing features of professionalism and professional ethics.

\section{SEND professionalism and professional ethics}

\subsection{Two types of professional ethics}

A key feature of traditional professional ethics is adherence to norms defined by a distinct professional body rather than by an employer. However, the notion of distinctive professions with their own sets of ethical principles has more recently been replaced by a new kind of accountability, where professional ethics is more likely to be equated with codes, rules and principles rather than internalised values (Shapiro \& Stefkovich, 2011).

Whilst little attention has been given to professional ethics in recent SEND literature, Banks (2014) examines the growth in interest in professional ethics in the related social work domain. She asks whether ethics is promoted as part of the resistance to an erosion of value-based professionalism by emphasising social justice and moral agency of professionals, or in order to ensure conformity by focusing on the regulation of the conduct of professionals through codes of ethics and practice. Ethics associated with regulation and 
conformity is marked by: (1) the development of increasingly lengthy and prescriptive codes; (2) the responsibilisation of professionals and service users; (3) a focusing of attention on relationships between individual professionals and service users away from critiquing social policy, including the framing of ethical issues as dilemmas for individuals; and (4) ethics as a contract between several parties conforming to externally defined standards, rather than based on mutual trust. The 2015 Code can be seen as implying this type of professional ethics. In contrast, ethics viewed as an important counterpoint to seeing professionals as technicians or bureaucrats (and service users as responsibilised consumers) is distinguished by: (1) a reclaimed professional relational autonomy which exercises discretion in decision making; (2) asserting the needs and rights, and respecting the choices of, service users; (3) exercising distributive justice as a political act; and (4) focusing on a situated and communal ethics.

This article seeks to explore the extent to which professionals are able to pursue a valuesbased professionalism implied by this type of professional ethics. The ethical audit described below seeks to further investigate the type of ethics promoted and practiced in relation to the 2015 Code, with particular reference to professional partnership working, although there is no suggestion that it addresses a simple binary between codes of practice and professional relational ethics.

\subsection{Professional codes}

Ethical principles are frequently codified to provide guidance on acceptable practice for individual professionals. This is done in a confusing array of codes of ethics, professional codes, professional standards and codes of professional practice. These codes address the circumstance that professionals are in positions of power (due to specialist knowledge or their executive powers) over individuals, who depend on their competence and integrity for support. Codes (1) define the overall aims of the profession (sometimes representing an idealistic goal and providing a sense of direction rather than describing practice); (2) act as a quality assurance mechanism by outlining good practice; (3) are regulatory by laying down minimum standards of conduct which may be used for disciplinary purposes; and (4) should engage professionals in their thinking and reasoning about professional aims (Schmit, 2006). Schmit further comments that codes may be of limited value if they are too abstract and 
vague and cannot be applied in practice, and recommends that they should be specific and capable of implementation, so that their application in practice can be seen, monitored, checked and evaluated. This seems a fair summary of how policy architects understand the SEND CoP 2015 and Schmit's assertion that codes of practice are simply codes of ethics known by a different name is a logical conclusion of this technicist view of ethical conduct.

Whilst there is a dedicated ethical code for professionals working in special education in the USA (CEC, 2006), there is no comparable code for professionals in England. Professionals engaged in SEND partnership working in England are guided by professional codes from their own professions, but this may contribute to conflicting priorities and challenge collaborations. Fox (2015) for example, writing from the perspective of an educational psychologist (EP), argues that the SEND CoP 2015 clearly conceives the child as the client, which therefore now allows EPs to take up a principled advocacy position. However, this may not be so easy for those EPs who work under service level agreements (SLAs) where local schools rather than individual children have in practice become the client. This repositioning for EPs may lead to more harmonious partnerships with parents, but will be at the expense of more challenging inter-professional collaborations. Ehrich et al. (2011) therefore point to the limited and limiting nature of codes, as they are "unlikely to provide answers to a complex multi-layered situation where there are competing responsibilities at hand" (p.175). Shapiro and Stefkovich (2011) additionally identify potential clashes between codes as problematic: between an individual's personal and professional code; between two professional codes where an individual operates across professional boundaries; clashes between two professionals; and between professional communities.

On a more theoretical level, Bauman (2008) argues that the case for normative regulations (including those expressed in professional or ethical codes) is founded on the ethical challenge that humans are exposed to by the very presence of others. Society in this view is a vehicle for reducing the unconditional and unlimited 'responsibility-for-the-other' to a set of agreements and prohibitions which reflect more realistically the limited human abilities to cope and manage. Unlimited responsibility and uncertainty is mitigated by "replacing the mind-boggling complexity of the task with a set of straightforward must-do and mustn't-do rules, rendering actions ethically neutral and exempting them from ethical evaluation and censure" (p.52). Normative regulations reduce the "infinity of ethical demand" (p.48) to a 
realistic task by making the responsibility limited, specific, codified and conditional. It results in conflicts "being managed in accordance with technicist approaches" (Gibson, 2009, p.12). Bauman and others lament this reductionist approach where ethical agency is replaced by a responsibilisation of individuals (xxx, 2017).

\subsection{Moral agency and professional judgements}

Less technicist approaches describe ethical professional action as action that utilises prior experience, welcomes new experiences, ideas and criticisms and learns from mistakes made, rather than as straighforward adherence to a pre-formulated code. Instead of becoming immune to morally relevant considerations by simply adhering to a code and so potentially morally stunted, professionals can and should assume moral agency and through this transform their relationships with colleagues and those they serve. A professional judgment is no longer "a decision about which rule to follow, but a reaction to the morally relevant aspects of the situation" (Dawson, 1994, p.151). Dawson argues that the attempt to codify professional activity in a technicist way may be unethical in itself, as it removes the responsibility for professional action from professionals. Instead, he advocates an educational model of ethical conduct where professionals are always learning in response to given situations and so hone their practice as moral agents. This is the change from 'outsidein' professionalism which pre-supposes articulated codes of professional and ethical conduct, to 'inside-out' professionalism relying on Aristotelian qualities of virtue. Whilst this binary conception may be "too morally obvious" (Stronach et al., 2002, p.113), it nevertheless supports a letting go of the "fantasy of once-and-for-all remedy for the dilemmas of professionalism" (p.125) by simply observing a statutory code. Rather, it requires accepting risk and uncertainty as an ethical necessity in professional practice. Tolerating risk assumes an acceptance of 'normative complexity' rather than the 'suspended morality' (Murray, 2013, p.76) offered to professionals by following the letter of a code.

The level of awareness professionals have of their moral agency is indicative of ethical knowledge, understood as practical wisdom distinct from technical competence (Campbell, 2003). Campbell cautions that "the point of ethics is not to moralise or to dictate what is to be done, but to find tools for thinking about difficult matters, recognising from the start that the world is seldom simple or clear-cut" (p.9). "Morally charged critical incidents" (p.22) can 
enable professionals to re-interpret actions they may have described merely as for example inefficient, or else pedagogically sound, and so recognise personal and professional moral agency and develop ethical knowledge. The lack of "competence in moral reasoning" (Shapiro \& Stefkovich, 2011, p.20) may limit educationalists to resort to practising professional ethics that are simplistically equated with codes, rules and principles, all of which may fit neatly into traditional concepts of justice but do not take sufficient account of relational complexities. Whilst professional codes may be valuable, it is likely that too much is expected of them with regards to daily moral professional decision making.

In this theoretical section, I have explored justifications for and limitations of professional codes. I have highlighted authors who argue that ethical knowledge (understood as an increasing awareness of moral agency), and a growing willingness to exercise moral professional judgements in the presence of uncertainty and risk, may be more conducive to supporting complex decision making processes and professional relationships than simply following a prescriptive code. I now describe my empirical project.

\section{Methodology}

My exploratory interpretive interview study draws on 16 in-depth, semi-structured interviews, lasting for approximately one hour each, that were conducted between October 2014 and February 2015. Participants occupied a range of professional roles relating to SEND from across education, health and social care agencies in 4 local authorities in England. The voluntary participation from 3 class teachers, 3 special educational needs coordinators (SENCOS), 4 SEND caseworkers, 3 SEND advisors and commissioners, 2 social workers and a child psychiatrist was secured by a snowballing system of recommendations. Of the professionals approached, 2 declined to participate and one participant withdrew her consent following the interview. Where the particular role and the level of experience of the participant is relevant, I indicate this in brackets and I use pseudonyms throughout. The study was conducted in accordance with the guidelines of the British Education Research Association (BERA, 2011).

The project asked participants about their early experiences of intensified partnership working under the 2015 SEND Code; to reflect more generally about enablers and barriers 
to partnership working; to identify specific new challenges encountered; and to discuss ethical concerns arising. Data was analysed by drawing on constructivist grounded theory approaches (Charmaz, 2014) that promote inductive and iterative engagement with data. For initial coding, I used a software programme for qualitative analysis (NVivo10) and the relevant nvivo nodes can be found in Appendix $A$.

I then employed Cribb \& Ball's (2005) ethical audit framework as an analytic tool for further exploring data discussed in this article. It utilises a three-dimensional ethical sensitising lens that draws on a range of theories from normative ethics. The framework aims to make ethical considerations arising from policy innovation explicit, with the intention to illuminate and sensitise rather than to prescribe action. The three suggested lenses, understood as heuristic tools, are those of goals (linked to consequentialism and its benefits analysis); obligations (linked to deontology and its sense of duty and 'what I ought to do'); and dispositions (associated with virtue ethics and an appraisal of worthy character traits). I will explore these further in the relevant sections below. In my discussion, I consider policy ethics which examines the intentions and defensibility of policy planners to re-focus or replace goals, obligations and dispositions through policy innovation; and ethical effects which examine how subjectivities are reconstructed and produce "a new ethical commonsense for action" (Cribb \& Ball, 2005, p.115). I also consider the division of ethical labour (Cribb, 2009) and implications for partnership working and the design of particular (the SENCO and the SEND caseworker) roles.

\section{Ethical audit: goals, obligations, dispositions}

\subsection{Alternative and competing goals}

The lens of goals is a form of cost-benefit analysis and refers to a weighing up of positive and negative consequences where decisions are required (Cribb \& Ball, 2005). One demand the 2015 Code clearly states is a child-centred professionalism where the best interests of the child are always privileged over professional interests and where positive consequences are always sought for the child, even if this results in negative consequences for distinctive professional identities and practices. Another shift is the new focus on outcomes, defined in the Code as "the difference or benefit made" to individuals (DfE and DoH, 2015, 9.66), and 
conceived as measurable positive consequences for the child, resulting from the interventions and provisions made by professionals.

\section{A child-centred versus a distinctive professionalism}

The central message of the 2015 Code is that professionals need to work together more effectively and need to adopt a child or family-centred focus where this is not already the case (DfE and DoH, 2015, 1.1). This child-centred focus relates to the ethical imperative that SEND professionals work together for the best interests of the child (Banks, 2014; Fox, 2015; Murray, 2013). For some participants, a child-centred focus is a fundamental professional and ethical value:

I think if you come back to focus on the child and their well-being, it cuts through a lot of the difficulty and the discouragement of the job because that brings me back to the right place and the right agenda and helps me to cut through some of the rubbish that I have to sometimes sit through and listen to. (AMY)

As an experienced social worker, AMY's training has ensured that her practice 'is very childfocused', thinking 'of the world and the situation through the child's eyes'. SEND caseworker LILLY also comments on a good partnership with the child at the centre, which in her case enabled conflicts to be contained:

It had nothing to do with liking, we both had the child at the centre of the conversation, always - even when it's a difference of opinion, the child is still at the centre. (LILLY)

Where partnership working goes wrong, the missing joint focus on addressing the child's best interests has been attributed as a cause:

I would say that the SEND [caseworkers] hadn't been child-focused in that [...] I felt really upset that people couldn't just be a bit creative and flexible about how they worked to meet her needs. (ISABELLA)

For newly-qualified social worker ISABELLA, this experience constituted a "morally charged critical incident" (Campbell, 2003, p.22). It foregrounded the conflict experienced by professionals between applying consistent standards demanded by an ethics of justice, and an ethics of care insisting on a response with genuine sensitivity to individual need. Murray 
(2013) highlights the importance of moral enquiry in this 'standards versus care' dilemma as particularly significant when considering moral aspects of pursuing the best interests of the child, as there is often no easy to achieve clarity or agreement about what actually constitutes a child's best interest. When exploring this dilemma, some argue that universal standards and rules harm the best care that individuals can benefit from, whereas others advocate that consistently applying rules provides the best protection against injustice and neglect. Both views were expressed by participants, but only as 'either or' positions. ISABELLA, for example, does not discuss the full spectrum of ethical positions that a more sustained engagement with moral enquiry could have offered to her sense-making of the distressing incident she described. This may also have supported more effective partnership working.

Whilst many participants, including AMY and ISABELLA, understand child-centeredness to be a fundamental professional attitude and necessary ethical response, others limit it to a technique:

We had some training from someone external for person-centred reviewing - so personcentred reviewing was obviously on the agenda there somewhere. (CARMEN)

A few participants rather want to hold on to prior ideas of a distinctive professionalism:

Professionals do different things, they are assessing for different things, we are assessing for what is going to happen in school - the education side of it. I mean the big old plan of having just one Plan, I just don't think is very practical. (GINA, experienced SEND caseworker)

People are coming from such different places, everybody thinks the way they do it suits them best, and they just don't fit together. (CARMEN, Experienced SEND caseworker)

Child-centred practices can threaten more traditional constructions of professional identities as autonomous experts with a distinctive knowledge base. SEND caseworker participants have alluded to this by commenting on requiring fewer skills for writing EHC Plans than before ('the writing of Statements was more skilled...', GINA) and preferring to work in isolation rather than through co-production practices ('I find it easier to write 
Statements, because nobody's interfering with what you're writing', NADIA). Whilst some professionals are indeed challenged by the policy effects of an intensified child-centred practice which reconstructs professional subjectivities, this could be seen as a justified ethical demand for facilitating SEND partnership working. The goal of promoting a childcentred practice, where the best interests of the child is the central concern for everyone involved, is recognised and defended as a good policy intention by many participants, including by some whose professional practices and preferences are challenged as a result of it.

\section{The value and values of outcomes}

The 2015 Code introduces an explicit shift away from evidencing specialist provision in support of meeting certain targets (documented in the superseded Statement of SEN), to focusing on aspirational outcomes that take a longer term view. These outcomes need to be co-produced with families and are documented in Section E of the education, health and care (EHC) Plan in a way that evidences the impact of provision, preferably in the form of specific, measurable, achievable, realistic and time-limited (SMART) targets. My participants are greatly exercised by this new goal and demonstrate a variety of responses. SEND Caseworker LILLY, like many other participants, welcomes this shift and its positive benefits for children:

Schools got a pot of money and that was it ...now it's like, 'Right, that's speech and language for one hour a week, what's the impact of that? Are they being able to communicate with you more? Are they able to express their needs?'. (LILLY)

For many, the shift from targets to outcomes is justified and welcomed as something that is more than merely a change in terminology or an unreasonable demand, because 'it's now about what the child can do as opposed to what they can't do' (LILLY), with an admission that before, 'sometimes you were looking at too little' (HANNA). ELLA explains why this might have happened:

People can become so scared about not meeting targets that they then instinctively...I don't necessarily think intentionally, but ... you keep them low and achievable, rather than that sense of, 'Where could we get this child to? Let's just try and get there'. (ELLA) 
ELLA recognises the beneficial effects of ambitious long-term outcomes for individuals and admits to the negative consequences of self-protective professional censure. She also highlights the potentially detrimental consequences of excessive accountability and scrutiny.

\subsection{A new prominence for some obligations}

The lens of obligations considers deontological reasoning and what is deemed to be part of the non-negotiable duties of a job. One example arising from the 2015 Code is the strengthened duty for class teachers to meet the needs of all students, other examples are the intensified obligations to enable effective parent-partnerships (see xxx, 2017) and interprofessional collaborations.

\section{A new obligation for teachers to meet the needs of all students}

The 2015 Code states that it is now the duty of the class or form teacher to accept overall and ultimate responsibility for the wellbeing and achievement of everyone in their class, including children with SEND (DoE and DoH, 2015, 6.36). This is welcome news for SENCOs:

The culture has shifted, and that's good, the sense that teachers are responsible for all of their children, and then you're working with other people to try to address those needs. (ELLA)

When the intervention was organised away from class teachers it was not effective because then they were not taking responsibility. (HANNA)

Class teachers working in the same schools, however, offer a very different perspective:

I know they are my responsibility. Even if a child has SEN, you have never been able to give that as an excuse, 'Oh, they can't make progress because they have SEN'. I do my best with the limited capacity I have, and I will continue to do that, and I have done so in the past. (BETTY, experienced class teacher)

Realising that legally there's the requirement there, but practically nothing's really changing... I know it's my responsibility..., but it's that whole legal thing that makes it a bit scary. (DAISY, experienced class teacher) 
Shifting obligations from one group of professionals to another group challenges partnership working and here some clear fault-lines appear:

What's frustrating is, I know that I've got children in this class who have been discharged by professionals as having no problem, and yet have huge barriers to their learning... And yet officially, there is no issue. (DAISY)

This kind of experience can very quickly lead to a deterioration of partnership working where, rather than professionals working together in a child-centred and collegiate way to find solutions for behaviours that challenge, responsibilised individuals are blamed. In this small study, it appears that the new obligation imposed on class teachers is felt as a heavy burden, both because of the statutory framing of the 2015 Code and the resulting performative demands, and also because of doubts whether identified needs can be contained and met in this way. For some of my participants, partnership working appears to be undermined rather than strengthened by shifting additional obligations onto individual class teachers. The felt and expressed undesirability of exploring some of these doubts in the interests of harmonious partnership working exacerbates this concern.

\section{Intensified obligations for enabling inter-professional collaboration}

Many participants express very positive attitudes towards professional collaboration. Whilst AMY 'loves partnership working and wouldn't describe partnership working as difficult', others acknowledge challenges. There are also more ambivalent voices which question the need for collaborative partnerships, especially where this presumes face to face meetings:

Part of our process is letting the panel look at all the EHC Plans, and all three agencies sign it off, but I don't know how realistically that can happen within the time frame, getting the Plans out and everything. [...] When you used to write a Statement, you didn't have to wait to get answers from all these people, whereas with this, it seems to slow it up. (NADIA)

GINA also thinks that 'where people need to come, they are coming, [...] it might just be that it is not necessary'. 
The 2015 Code explicitly repositions some professional roles from horizontal, collegial relationships to more vertical, hierarchical ones and this changes the nature and dynamics of partnerships, which is not always welcome and may produce strong affective responses. The SENCO role, for example, is now firmly established as a senior manager with a strategic (and arguably managerialist) role, rather than an experienced fellow practitioner who can support and guide:

I really struggled with what to do. I felt frustrated and I was standing on the edge thinking, I don't know what to do, I don't know how to get this going. I was like, how do I get the teachers to do this? You just feel in the dark sometimes, you know, even though I studied. I did the SENCO accreditation. (HANNA, inexperienced SENCO)

For HANNA, the feeling of 'being in the dark' and being unsure about 'how to get this going' is unacceptable as she assumes that gaining accreditations should have equipped her with certain knowledge about what to do, including how to exact partnership working from unwilling colleagues.

\subsection{Cultivation of 'new' dispositions}

A third ethical lens is that of 'dispositions', which focuses on characteristics and character traits of the 'good SEND professional' and how these are cultivated by individuals and organisations. The introduction of the 2015 Code has accelerated the need to embrace change and can leave individuals feeling exposed and option-less. I look at this responsiveness to change as one of a more troubling example of reconstructed subjectivities that produce "a new ethical commonsense for action" (Cribb \& Ball, 2005, p.115):

It is daunting because it is change, and it was comfortable how things were before. I mean we know it is really important, but all these new things that get put on you all the time, and you go, 'Ahh, help'. (JACKIE, inexperienced class teacher)

I don't like being out of control, that's me personally, and I would rather have had time to have embedded some stuff before we started, but that's my personal work style. (OLGA, inexperienced SEND caseworker) 
People were press-ganged into doing it, they didn't want to do it but had to do it, it was just added onto their jobs. (GINA, experienced SEND caseworker)

I didn't necessarily want to go into the younger ones but I'm thinking, 'Oh give it a go and see'. I will do it, I might be a bit hesitant because I think my role is constantly changing and you constantly have to adapt. It might take you a little while to get there, because I don't think things are safe as such. (KEZIA, experienced inclusion advisor)

GINA comments on multiple changes that 'drove us into a complete state of anxiety, really', which resulted in her case in 'just adapting to it', but for those who couldn't, in early retirement and redundancies. For all these professionals, it is evident that whatever their personal preferences for continuity or change, and for risk-taking or feeling safe are, as professionals working in the current climate there is only one valued disposition which they need to embrace, even if it entails high personal costs. The frequently demanded welcoming of 'disruption and discomforts' in literature which is advocated as a means of improving partnership working as well as inclusive practice (Ainscow, Booth \& Dyson, 2006; Frost, Robinson \& Anning, 2005) may result in individuals being unable to consider their own wellbeing.

\section{The division of ethical labour as partnership practice}

In their attempts to negotiate conflicting values, expectations and responsibilities, most of my participants pursue the path of "ethical differentiation" (Cribb, 2009, p.32) which "splits off' and limits personal moral responsibility based on the role occupied at the time. OLGA, for example, describes herself as 'poacher turned gamekeeper' to reflect the various roles and responsibilities she has had over the years in relation to parents: from supporting parents in opposing professional judgements ('...in the end, we had to support them in what they wanted to do'); to supporting other professionals ('I told them, if you've got a review coming up and you think a problem might be brewing, perhaps we should come'); or dealing with parents directly in a potentially confrontational role ('I do realise they're not going to love me like they used to, because I'm now the enemy'). For OLGA, it is clear that a particular 
role makes particular ethical demands on her, but also that these roles carry the limits of ethical responsibility within them.

BETTY identifies an unethical practice perpetuated in order to achieve performative goals:

The extra help in the form of a TA - when I have one - is directed at those children we can move on, who can get their expected level, so it can't be in inverted commas wasted on someone who won't be able to achieve this, and that is frustrating and unethical. (BETTY)

However, she limits her responsibility by concluding: '...but you can only do what you can do, what you are capable of' and provides an interesting example of 'bracketing' (Hammersley-Fletcher, 2015, p.205) which allows individuals to function despite the coexistence of contradictory beliefs.

Whilst individuals clearly feel constrained by persisting hierarchies ('I felt limited in how much I could challenge that, because on the hierarchy I'm lower down, so it got to a point where I just thought, you know, I can't really challenge anymore, because they're senior', ISABELLA), many consciously self-limit their responsibilities and are satisfied that by actively expressing concerns, they have done their duty:

I don't want to leave a meeting thinking I should have said something...so now I just say, 'Well actually, this is what I think'. I think I need to say it for that child. Once I've said it, ...I can't change an outcome. I can put my point of view across but I can't really change the outcome. (KEZIA)

I think voicing it, I've felt has been enough. (MINA)

This self-imposed restricting of independent ethical agency is importantly not the same as denying any personal moral responsibility for decisions:

Say you did agree with the parents, but ultimately, you aren't making the decision. I'll make sure people know what my view is internally, even if I don't share that with the parent. If I really believe something, I won't leave something alone. (OLGA) 
I'm sure there'll come a day when she [the manager] wants us to write something that one of us is going to absolutely refuse to write. (OLGA)

Often, the deliberate bracketing of knowledge and the resulting limitation of responsibility is employed as a coping mechanism in demanding circumstances:

It [the new demands of the Code] does panic me a bit, but not too much, I can isolate it anyway. (JACKY)

There are so many things to juggle as a class teacher, and this is one more. [...] At the end of the day that's what I want, I want to know how it's going to affect me in the classroom as the class teacher. (DAISY)

There is clearly a lot that I have not been involved with, party to or interested in, because for me there is enough to do working day to day. (CARMRN)

The division of ethical labour for OLGA is not only about her own coping, but rather about building and maintaining valued relationships for effective partnership working:

I'm not making decisions, that's not what l've got to do, I've got to gather the facts, I've got to listen, I've got to try and sort things, but I'm not a decision maker... I wouldn't want to be that person, because I've got to work with those people day to day, I need to maintain a relationship. (OLGA)

Many other participants also negotiate conflicting values and potential conflicts with partners by compartmentalising in this way:

That's who I'm thinking about. I might go the next day to another school, to another child, but it's that child at that particular point in time. (KEZIA)

For some participants, advocacy that focuses on an individual child is the most important aspect of their role and a "socially sanctioned partiality" (Cribb, 2009, p.36) is therefore reasonable and morally defensible, whilst others must retain a judgement of "global impartiality" (p.36) because the focus of their role is to maximise the benefit for most. Where roles clearly fall into one or the other category, participants seem to judge their 
professional practices as ethically sound. I demonstrate this by considering the contrasting roles of FLORA and NADIA.

Experiencedd improvement officer FLORA discusses moral dimensions of her role only reluctantly:

What you give to one family, there are implications for other families, so there are very difficult moral choices. But it is economics, opportunities and costs, in terms of what you can spend here you can't spend there with diminishing resources, so you have to come up with smart and clever solutions where you possibly can. That is probably where you get into the very real ethical/pragmatic decisions. (FLORA)

For her, the solution does not lie in deliberating difficult moral choices, but rather in being ethically pragmatic by following market logics. In her role, which is some distance from individual cases, smart solutions that make economic sense may not only be judicious, but ethically consistent with the 'globally impartial' role she occupies, maximising benefit for the most.

However, the unburdening that comes with pursuing a role-relative, differentiated professional ethics exemplified by FLORA, as well as KEZIA and OLGA for example, appears not to be possible for some participants because of the particular design of their roles. The remits of SENCOs and of senior SEND caseworkers in LAs have been re-shaped by the 2015 Code: the SENCO role has become more strategic; SEND caseworkers are now more involved in individual cases because of the emphasis on person-centred planning for EHC Plans. They therefore might want to resort to a 'partiality' that comes with knowing individual cases in depth, whilst simultaneously being charged with retaining 'global impartiality' in order to deliver outcomes within a legal framework that is audited and inspected:

When you wrote a Statement, you just got all the advice and you wrote it, you never met the child, you never met the parents... so it is very, very different. (NADIA, SEND caseworker)

This is not simply a comment on the mechanics of writing up the new EHC Plan. In the new policy settlement NADIA's reconstructed role requires her to spend considerable time 
getting to know and working with parents and their experiences. Where this results in conflict, she is aware that there isn't the time to negotiate a collaborative compromise, as discussions must be brought to a timely conclusion: 'The hardest thing was, I had, in the back of my mind, the time ticking away in which I had to write this Plan'.

Her solution is 'trying to de-sensitise yourself from that', although she admits that she hasn't managed this very well because she doesn't know how. A previous study (xxx, 2014) has highlighted how some SEND caseworkers are able to respond to moral complexity and are willing to carry significant moral burdens in order to meet the needs of children, but that this is accompanied by often unrecognised experiences of moral stress, brought about by seeking to embody conflicting virtues. This is also true for NADIA.

\section{Implications for professionalism, professional decision making and partnership working}

Potentially incompatible values may not be recognised as incompatible because the corresponding requirements all seem reasonable. One example is the Code's ambition to provide consistency and comparability and with it greater equity by putting an end to the documented 'postcode lottery' of provision and experiences for parents (Lamb, 2009). For this reason, uniformity of processes within stipulated time frames that are externally audited and standardised provision for groups of children are upheld as the best guarantee to ensure consistency. This directly contradicts the equally valuable ambition to respond to individual need and preference in the 2015 Code's exhortation that adherence to published criteria must not foreclose response to individual need (DfE and DoH, 2015, 9.16). For frontline professionals, responding to both aspirations may seem impossible. However, a consideration of the ethical concept of distributive justice may support an accommodation of these competing values but necessitates understanding and use of normative ethical theories (Murray, 2013) by SEND professionals. This cannot currently be presumed due to the lack of habitual exposure to ethical discussions and deliberations. Distributive justice allows for differences in the allocation of resources, but only on the basis of inequalities, rather than by arbitrary measures. Addressing these inequalities may mean that allocation should go to the child with the most need or else to the child where resources will make the greatest difference (Fox, 2015). My data shows how unaccustomed participants are to utilise this kind of ethical thinking in their professional discourse and partnership work. 
Only a few participants frame their reflections about changing demands and difficult decisions as ethical challenges, and some are reluctant or unable to engage with ethical discourse at all. One telling example is OLGA who self-censures her use of the word 'compassion' ('I don't want to use the word compassion... and also you just cannot get too emotional about it') as a seemingly inappropriate affective response in a professional context. Whilst participants express "hints, traces, murmurings of moral disquiet and subtle discontents, ....there is no discourse of critique through which such concerns can be coherently expressed and recognised as valid and valuable" (Ball et al., 2011, p.617f).

Most participants welcome the new goal of being outcome-focused, although some recognise that it comes with assumptions that need to be named and maybe resisted. This includes the assumption that evidence-based practice produces outcomes that can be determined in advance (Biesta, 2007 cited in Urban, 2008). The Code's problematic construction of a SEND professionalism that can deal with clearly diagnosable and definable problems, can formulate pre-determinable outcomes and achieve these through evidencebased practices that are regulated via a statutory code fails to acknowledge the fundamental precariousness of outcomes for children with complex needs. Fox (2015) therefore suggests a departure from evidence-based practice to one of integrating best research evidence with expertise and values and promotes 'practice-based evidence' from which to work. This necessitates a clear articulation of values and an acceptance of uncertainty and doubt as integral to ethical professional practice which is currently not normally promoted or sought after.

Accepting that "what makes the moral self is the urge to do, not the knowledge of what is to be done; the unfulfilled task, not the duty correctly performed" (Bauman, 1993, p.80) could support professionals in wrestling with issues of inherent uncertainty in articulating and pursuing outcomes that are in the best interests of the child. It may embolden them to risk more in favour of 'what could be achieved' (ELLA), rather than to engage in some of the limiting practices participants discuss which arise from insecurities caused by performative regimes. ELLA sums up this attitude when exhorting herself and others to '...let's just go for it. And actually, no-one's head is going to be on the block if we don't meet this...'.

\section{Conclusion}


In this article I have addressed some of the ethical challenges encountered by SEND professionals in response to demands made by the SEND CoP 2015 (DfE and DoH, 2015) and have considered how this may impact on partnership working. I have employed the three conceptual ethical lenses of goals, obligations and dispositions to examine data in order to make explicit ethical effects arising from SEND policy innovations and have discussed their defensibility. Considerations include a welcome re-orientation to work together for the best interests of the child, even if it challenges forms of distinct professional identities; and a focusing on outcomes rather than on provision. The focus on outcomes necessitates a difficult balancing act between embracing uncertainty as an unfamiliar professional practice and adjusting to target-driven outcomes which could be informed by 'practice-based evidence' (Fox, 2015) rather than 'evidence-based practice' promoted in current policy solutions.

I have also problematised the class teachers' new responsibility of meeting the needs of all students, as well as the intensified demands on partnership working across agencies. I suggested that those participants who have articulated a more coherent ethical knowledgebase were more able to negotiate conflicting values and demands arising from policy changes. In considering the division of ethical labour, which many participants employ as a means of coping with professional demands, I have highlighted particular roles where this division appears no longer possible, with problematic consequences for personal wellbeing and collaborative partnership working.

Professionals working in SEND partnerships occupy different ethical positions. This may include that some will privilege a consideration of 'the greatest good for the most' and will therefore tend towards ensuring statutory compliance and budget decisions which maximise benefits for whole groups as an ethical response. Others may focus on the most benefit for an individual', informed by offering compassion or insisting on individual rights. Many participants enact this differentiation self-defensively to support coping. However, they do not currently consider it as a way of improving partnership working by a allowing for appropriate responses to contrasting positions. Understanding various partnership roles and how they are similar and different from each other - not only in terms of divergent professional discourses, systems and practices, but also in "the ways in which ethical positions are embedded in occupational roles" (Cribb, 2009, p.41) through their very 
construction and the way these are occupied by individuals - may be an important but neglected aspect of enabling SEND partnership working.

The pressure points arising from the reformulated 2015 Code appears to be for SENCOs in schools and senior SEN caseworkers in LAs, with SENCOs taking on a more strategic role in school whilst still advocating for individuals and caseworkers being drawn into the coproduction model which increases direct engagement and advocacy of individual cases. In my small study, they, more than others, find themselves at the intersection and contradictions between needs and resources. Further research into diverse approaches to and understandings of a division of ethical labour for SEND professionals would be a fruitful area of study.

Ethical division of labour accepts the socially constructed nature of professional ethics where responsibility for it belongs as much with those who construct roles, as it does with those acting within them (Cribb, 2009). Those who construct or re-construct roles, such as the SENCO and senior SEN caseworker roles encountered in this study, have therefore a responsibility to consider ethical implications of this reconstruction. They must consider whether a division of ethical labour as a way of guiding professional decision-making and supporting partnership working, as well as for personal coping, remains a possibility for individuals.

Some participants recognise themselves as flawed and limited ('you can only do what you can do, what you are capable of') because of pressures from institutional norms and because of personal histories and characteristics. This may justify the regulatory conception of shared decision making envisaged in the 2015 Code, as it seeks to limit potentially flawed professional power through prescriptive instructions. However, it may also "shut off some of the most important resources available, namely those that arise from the personhood of professionals and the broad potential of supportive human relationships" (Cribb \& Entwistle, 2011, p.217). It relies on skills and virtues of individual professionals (as well as on realised capabilities of parents and responsible legislators and employers), and these need to be actively developed and fostered by individuals and organisations in order to grow the capacity to articulate values and justifications for recommendations as well as for negotiating demands, dilemmas, conflicts, and uncertainties. There is a marked difference in 
my participants' ability to articulate these values and justifications. Whilst some demonstrate a willingness to convey alternative visions and values, others deliberately and defensively limit their engagement and may with it contribute to an undermining of their own professionalism and certainly their ethical agency.

This article highlights how the new SEND framework may tempt professionals to equate ethics with conformity to the regulations of a statutory code, offering standardisation and the lure of following 'straightforward' rules as a way out for professionals who are caught up in contradictory demands. This is despite the findings in Munro's (DfE, 2011a) influential review that an "over-standardised system [...] cannot respond adequately to the varied range of children's needs" and her concern that "for some, following rules and being compliant can appear less risky than carrying the personal responsibility for exercising judgement" (p.11). Banks (2014) notes that "ethics is definitely not about simply following rules - it is about questioning and challenging, feeling and acting...it entails working in spaces between the contradictions of care and control, prevention and enforcement, empathy and equity" (p.21). My contention is that the 2015 Code simply understood as an instruction manual for hard-pressed or under-performing professionals does not focus sufficiently on the inherent risks that professionals should be willing to carry and must be equipped to bear. My aim for this article was to demonstrate how an ethical audit of policy solutions to identified problems can challenge professionals and those who design their roles to look beyond immediate implementation concerns.

\section{References}

Ainscow, M., Booth, T. \& Dyson, A. (2006) 'Inclusion and the standards agenda: Negotiating policy pressures in England', International Journal of Inclusive Education, 10(4), 295-308.

Ball, S. J., Maguire, M., Braun, A. \& Hoskins, K. (2011) 'Policy subjects and policy actors in schools: Some necessary but insufficient analyses', Discourse: Studies in the Cultural Politics of Education, 32(4).

Banks, S. (2014) Ethics: Critical and radical debates in social work. Bristol: Policy Press.

Bauman, Z. (1993) Postmodern Ethics. Oxford: Blackwell.

Bauman, Z. (2008) Does ethics have a chance in a world of consumers? Cambridge, MA: Harvard University Press. 
BERA (British Educational Research Association). (2011). Ethical guidelines for educational research. London: BERA.

Campbell, E. (2003) The ethical teacher. Maidenhead: Open University Press.

CEC (Council for Exceptional Children) (2006) Special education professional ethical principles. Retrieved May 10, 2015, from https://www.cec.sped.org/Standards/Ethical-Principlesand-Practice-Standards

Cribb, A. (2009) 'Professional ethics: Whose responsibility?' In S. Gewirtz, P. Mahony, I. Hextall and A. Cribb (Eds.), Changing teacher professionalism: International trends, challenges and ways forward (pp.31-42). London: Routledge.

Cribb, A. \& Ball, S. (2005) 'Toward an ethical audit of the privatisation of education', British Journal of Educational Studies, 53(2), 115-128.

Cribb, A. \& Entwistle, V. (2011) 'Shared decision making: Trade-offs between narrower and broader conceptions', Health Expectations, 14, 210-219.

Dawson, A. J. (1994). Professional codes of practice and ethical conduct. Journal of Applied Philosophy, 11(2), 145-153.

DfE (Department for Education) (2011a). Munro review of child protection: Final report - $a$ child-centred system. London: HMSO.

DfE (Department for Education) (2011b) Support and aspiration: A new approach to special needs and disability - a consultation. London: HMSO.

DfE and DoH (Department for Education/Department of Health). (2015) Special educational needs and disability Code of Practice: 0 to 25 Years. Retrieved 30 July, 2015, from https://www.gov.uk/government/uploads/system/uploads/attachment_data/file/398815/S END_Code_of_Practice_January_2015.pdf

Ehrich, L. C., Kimber, M., Millwater, J. \& Cranston, N. (2011) 'Ethical dilemmas: A model to understand teacher practice', Teachers and Teaching: Theory and Practice, 17(2), 173-185.

Frost, N., Robinson, M. \& Anning, A. (2005) 'Social workers in multidisciplinary teams: Issues and dilemmas for professional practice', Child and Family Social Work, 10, 187-196.

Fox, M. (2015) “What sort of person ought I to be?' - Repositioning EPs in light of the Children and Families Bill', Educational Psychology in Practice, 31(4), 382-396.

Garratt, D. \& Forrester, G. (2012) Educational policy unravelled. London: Continuum.

Gewirtz, S. \& Cribb, A. (2006) 'What to do about values in social research: The case for ethical reflexivity in the sociology of education', British Journal of Sociology of Education, 27(2), 141-155.

Gibson, S. (2009) 'Inclusion versus neo-liberalism: Empowering the 'other'. In S. Gibson \& J. Haynes, Perspectives on participation and inclusion (pp.11-26). London: Continuum Books. 
Norwich, B. (2014) 'Changing policy and legislation and its effects on inclusive and special education: A perspective from England', British Journal of Special Education, 41(4), pp. 404425.

Murray, D. (2013) Professional school leadership: Dealing with dilemmas. London: Dunedin Academic Press.

Schmit, C. (2006) A code of ethics for people working with children and young people. Retrieved May 10, 2014, from http://www.ances.lu/index.php/fice/sarajevo-2006/69-acode-of-ethics-for-people-working-with-children-and-young-people

Shapiro, J. P. \& Stefkovich, J. A. (2011) Ethical leadership and decision making in education: Applying theoretical perspectives to complex dilemmas (3rd ed). Abingdon: Routledge.

Stronach, I., Corbin, B., McNamara, O., Stark, S. \& Warne, T. (2002) 'Towards an uncertain politics of professionalism: Teacher and nurse identities in flux', Journal of Education Policy, $17(1), 109-138$.

Urban, M. (2008) 'Dealing with uncertainty: Challenges and possibilities for the early childhood profession', European Early Childhood Education Research Journal, 16(2), 135152.

Appendix A

\begin{tabular}{|l|l|l|}
\hline Professional Ethics in SEND & No of participants & No of comments \\
\hline 1 Empathy with Parents & 12 & 20 \\
\hline 2 Ethical Knowledge & & \\
\hline (Lack of)Awareness of moral dimension & 2 & 3 \\
\hline Ethical conversations & 4 & 7 \\
\hline Grappling with presenting challenges & 6 & 6 \\
\hline Vocation vs Institution & 2 & 2 \\
\hline 3 Ethical leadership & 4 & 8 \\
\hline Children getting a fair deal & 1 & 2 \\
\hline Ethical pragmatism & 1 & 3 \\
\hline 4 Moral dilemmas and moral stress & 6 & 17 \\
\hline Exaggerating or underplaying for results & 3 & 4 \\
\hline Getting involved and then having to let go & 2 & 2 \\
\hline Protective Behaviours for Self & 4 & 5 \\
\hline Subscribing to own ethical code & 4 & 11 \\
\hline Professionalism and Role Occupation & & \\
\hline 1 Role Occupation & & \\
\hline Current professional roles & 16 & 22 \\
\hline Disaffection with own role & 2 & 2 \\
\hline Enthusiasm and vision for own role & 2 & 2 \\
\hline Professional identification with SEN & 8 & 11 \\
\hline Professional status of new roles created following CoP & 4 & 7 \\
\hline Sense of ownership over own role & 3 & 5 \\
\hline & & \\
\hline
\end{tabular}




\begin{tabular}{|c|c|c|}
\hline 2 Professional skills, knowledge and training or lack of & & \\
\hline Being able to write the EHCP & 5 & 11 \\
\hline Evidence of misunderstandings of SEN & 7 & 12 \\
\hline Grasping the big picture but not knowing the detail & 1 & 3 \\
\hline Having the necessary skills set & 3 & 5 \\
\hline Knowledge of SEN CoP and Children Act & 11 & 26 \\
\hline Multidisciplinary Training & 3 & 5 \\
\hline \multicolumn{3}{|l|}{3 Embracing Professionalism } \\
\hline Accepting professional responsibility and accountability & 11 & 20 \\
\hline Always learning and adopting an active learning culture & 6 & 12 \\
\hline Learning by accessing online support & 5 & 6 \\
\hline Learning by doing & 6 & 8 \\
\hline Learning from other professionals in meetings & 3 & 5 \\
\hline Professional curiosity & 5 & 6 \\
\hline Anticipating problems & 2 & 2 \\
\hline Complexity and uncertainty welcome & 5 & 10 \\
\hline Dealing with change & 8 & 26 \\
\hline Dealing with frustration & 3 & 7 \\
\hline $\begin{array}{l}\text { Making a professional judgement whether contribution is needed or } \\
\text { priority }\end{array}$ & 1 & 4 \\
\hline Professional confidence & 15 & 31 \\
\hline Professional dialogue & 5 & 6 \\
\hline Professional dissatisfaction as means for change & 2 & 2 \\
\hline Professional optimism & 2 & 6 \\
\hline Understanding and respecting other professional roles & 13 & 24 \\
\hline \multicolumn{3}{|l|}{4 Challenges to Professionalism } \\
\hline Doubt in others' competence & 8 & 14 \\
\hline Lack of professional power & 1 & 4 \\
\hline Maintaining professional boundaries & 7 & 15 \\
\hline Professional anxiety & 7 & 12 \\
\hline Professional deskilling & 7 & 10 \\
\hline \multicolumn{3}{|l|}{5 Personal limitations to professionalism } \\
\hline Deliberate limiting of scope and working on a 'need to know' basis & 6 & 17 \\
\hline Individual professional and role competence & 8 & 12 \\
\hline Just doing as you are told & 3 & 5 \\
\hline Needing to be in control & 2 & 4 \\
\hline 6 Professionalism and Localism & 6 & 10 \\
\hline
\end{tabular}

